\title{
Effects of fat inclusion in starter feeds for dairy calves by mixing increasing levels of a high-fat extruded pellet with a conventional highly fermentable pellet
}

\author{
H. Berends, ${ }^{*}$ M. Vidal, $†$ M. Terré, $†$ L. N. Leal, ${ }^{*}$ J. Martín-Tereso, ${ }^{*}$ and A. Bach $†{ }^{1}$ \\ *Trouw Nutrition R\&D, PO Box 299, 3800 AG, Amersfoort, the Netherlands \\ tDepartment of Ruminant Production, Institut de Recerca i Tecnologia Agroalimentàries (IRTA), 08140 Caldes de Montbui, Spain \\ łInstitució Catalana de Recerca i Estudis Avançats (ICREA), 08010 Barcelona, Spain
}

\begin{abstract}
The objective of this study was to evaluate the effect of inclusion of an extruded high-fat pellet mixed with a conventional pelleted calf starter on energy intake and performance around weaning in calves. To this end, 75 female Holstein newborn calves $(41.0 \pm 4.98 \mathrm{~kg})$ were randomly assigned to 1 of 5 iso-nitrogenous solid feed treatments consisting of 4 levels of fat inclusion by mixing a low-fat highly fermentable control pellet with 3 different levels of inclusion of an extruded high-fat pellet [control (100:0), 90:10, 80:20, and 70:30], and a high-fat single pellet (HFSP). The HFSP was equivalent isoenergetic and iso-nitrogenous, although it had almost 1 percentage point difference in fat relative to the $80: 20$ treatment, to contrast the effect of the dual-component pellet mixture. The extruded high-fat starter feed contained a high proportion of fat $(38 \%)$, mainly from hydrogenated palm fatty acids. Calves were offered a milk replacer up to $900 \mathrm{~g} / \mathrm{d}$, and then pre-weaned at $49 \mathrm{~d}$ of age by halving milk allowance until $56 \mathrm{~d}$ when calves were weaned. Calves had ad libitum access to the starter diets, chopped straw, and water. Individual milk replacer and starter intakes were recorded daily and BW was determined weekly. A glucose tolerance test was performed at 49 and $84 \mathrm{~d}$ of age to evaluate blood glucose homeostasis. Apparent total-tract digestibility was determined from 70 to $75 \mathrm{~d}$ of age. Calves on the 90:10 treatment had greatest starter feed intake mainly due to a marked increase in solid feed intake around weaning. Metabolizable energy intake was increased when the extruded pellet was included in the starter. No differences were present in digestibility of ether extract among solid feed treatments. The area under the
\end{abstract}

Received May 25, 2018.

Accepted August 27, 2018.

${ }^{1}$ Corresponding author: alex.bach@icrea.cat curve of blood glucose concentration after the glucose tolerance test was greatest in 80:20; intermediate in 70:30, HFSP, and control; and lowest in 90:10 calves. No differences were observed for insulin or other parameters related to blood glucose homeostasis. Delivering dietary fat by mixing an extruded high-fat pellet with a conventional highly fermentable pellet to reach a total fat content of $7 \%$ results in increased starter intake, energy intake, and body weight gain until $84 \mathrm{~d}$ of age compared with a conventional low-fat pellet, or a single pellet with increased fat content.

Key words: calf, extrusion, solid feed, weaning stress

\section{INTRODUCTION}

Dairy calves are born without a fully functioning rumen, and they initially rely on milk or milk replacer (MR) to obtain the necessary nutrients to sustain growth (Khan et al., 2016). Irrespective of physical presence of the dam, ad libitum consumption of milk or MR has been reported to reach a maximum of around $12 \mathrm{~L}$ of milk per day (Jasper and Weary, 2002; Berends et al., 2016), distributed in $>6$ meals/d (Berends et al., 2016). In commercial dairy production systems, calves are transitioned from milk to solid feed as early as possible to minimize labor costs. Early weaning methods were traditionally developed based on the encouragement of solid feed intake by restricting milk feeding below $50 \%$ of ad libitum intake (Bach et al., 2017). Over the past decade, the industry has shifted toward greater milk supply in early life because of greater growth and feed efficiency in early life, increased longterm survival (Bach, 2011), and lifetime milk production (Bach, 2012; Soberon et al., 2012). However, large milk allowances delay solid feed intake, and thus rumen development (Terré et al., 2007) and growth around weaning (Cowles et al., 2006; Terré et al., 2006; Eckert et al., 2015).

Research on starter feeds has mainly focused on stimulating solid feed intake (Khan et al., 2011) to 
foster the initiation of rumen fermentation and accelerating rumen development (Baldwin et al., 2004). Only recently, Araujo et al. (2014) demonstrated benefits of increasing energy content of solid feeds by inclusion of full-fat soybean in pelleted starters when providing 750 $\mathrm{g} / \mathrm{d}$ of MR. Fat inclusion in starter feeds has commonly been disregarded because it may negatively influence rumen development as it provides energy to the calf but not to rumen bacteria (or very little). Furthermore, when fat and fermentable ingredients are combined in one pellet, fat may physically impregnate fermentable components, limiting bacterial access to these particles and thus hampering potential microbial growth and rumen development. Rumen inert fat sources are available in the form of hydrogenated fat prills and calcium soaps, and are commonly used to overcome technological limitations associated with fat inclusion in pelleted feeds. First, these fat sources lose their physical form when they melt during the pelleting process and soak or coat other feed components, which in calves has been shown to compromise intake (Kazemi-Bonchenari et al., 2016). Calcium soaps also appear to be detrimental to solid feed intake (Fallon et al., 1986), and at high inclusion rates (i.e., $>3 \%$ ) pellet quality is impaired (Thomas et al., 1998). Feeding rumen inert fats separate from the pellets is not an option because of their poor palatability, and homogeneous mixing to prevent sorting is unfeasible because their particle size is much smaller in comparison with pellets. Alternatively, extrusion and vacuum coating feed technology allows for high inclusions (e.g., 30-60\%) of fat in pellets, which is a common practice in fish and pet feed manufacturing, but not used for calf starters. The similar size of these pellets offers an opportunity to homogeneously mix them with conventional pellets, preventing sorting by calves, and in this way facilitate the inclusion of fat in solid feeds for calves.

The underlying hypothesis of the study was that supplying increasing levels of fat in starter feeds along with generous amounts of MR would improve performance of young calves. Furthermore, offering fat in a separate pellet and then mixing it together with another pellet rich in carbohydrates would increase the energy content of the TS feed offered to calves without impairing rumen fermentation and compromising feed palatability. Therefore, the objective of the current study was to evaluate the effects on performance between birth and 4 wk postweaning of different levels of fat supplementation in starter feeds by combining conventional low-fat pellets with a high-fat pellet (manufactured by extrusion and vacuum coating technology), and to contrast this with simply adding an equivalent amount of fat to a complete pellet.

\section{MATERIALS AND METHODS}

\section{Animals and Feeding Program}

A total of 75 female Holstein newborn calves (41.0 $\pm 4.98 \mathrm{~kg}$ of $\mathrm{BW}$ ) from a single farm were enrolled in this study between March and June 2016. Calves were managed under common animal management conditions under the supervision of Institut de Recerca i Tecnologia Agroalimentàries technicians and the approval of the Animal Care Committee of Institut de Recerca i Tecnologia Agroalimentàries (Barcelona, Spain). Calves were individually housed in hutches $(1.20 \times 1.45 \mathrm{~m})$ with access to an outdoor area $(1.20$ $\times 1.25 \mathrm{~m}$ ) equipped with one bucket for water, one for concentrate, and one for forage. Hutches were bedded with sawdust on a daily basis and calves were bottle-fed MR. Within the first $6 \mathrm{~h}$ of life, calves received $3.5 \mathrm{~L}$ of colostrum (previously thawed) using an esophageal tube. Colostrum quality was tested for density using a colostrometer and only colostrums with $>50 \mathrm{mg} / \mathrm{mL}$ of $\mathrm{IgG}$ were frozen and used in this study. Calves were fed $3 \mathrm{~L}$ of MR (Sprayfo Excellent, Trouw Nutrition, Deventer, the Netherlands) containing 23.2\% CP (all of milk origin) and $18.6 \%$ fat (on a DM basis) twice a day at $12.5 \%$ concentration of MR powder $(750 \mathrm{~g} / \mathrm{d}$ as fed) for the first week, and then 2 meals of $3 \mathrm{~L}$ at $15 \%$ concentration (900 g/d as fed) until $49 \mathrm{~d}$ of age. Then, MR was limited to a single offer of $3 \mathrm{~L}$ also at $15 \%(450$ $\mathrm{g} / \mathrm{d}$ as fed) until $56 \mathrm{~d}$ when calves were fully weaned. For the duration of the study ( $84 \mathrm{~d}$ ), calves had ad libitum access to water, pelleted starter feed, and chopped (about $3.0 \mathrm{~cm}$ in length) barley straw (2.6\% CP, 80.5\% NDF, and $51.8 \%$ ADF on a DM basis).

\section{Solid Feed Treatments}

Calves were randomly assigned to 1 of 5 iso-nitrogenous solid feed treatments consisting of 4 levels of fat inclusion by mixing a low-fat control pellet with different proportions of an extruded high-fat pellet [control (100:00), 90:10, 80:20, and 70:30] leading to target final fat concentrations of the pellet mix of 3.5, 7.0, 11.0, and $14.0 \%$ (DM basis), respectively, as well as a high-fat single pellet (HFSP) with a fat (11\%), protein, and energy content equivalent to the 80:20 treatment, to contrast the effect of the dual-component pellet mixture against a high-fat single-pellet. Table 1 depicts the composition of the 3 pelleted feeds, and Table 2 shows the relative mixture proportions of each pellet and the analyzed nutrient composition of the 5 solid feed treatments.

Pelleted feeds were produced (Forfarmers, Lochem, the Netherlands) with a pellet die diameter of $5 \mathrm{~mm}$. 
Table 1. Formulated ingredient and analyzed nutrient composition of the 3 pelleted feeds used to compose the 5 solid feed treatments

\begin{tabular}{|c|c|c|c|}
\hline \multirow[b]{2}{*}{ Item } & \multicolumn{3}{|c|}{ Pellet type } \\
\hline & Low fat & High-fat extruded & High-fat single pellet \\
\hline \multicolumn{4}{|l|}{ Ingredient, $\%$ of DM } \\
\hline Corn & 34.7 & 12.5 & 30.2 \\
\hline Soybean hulls & 13.6 & & 11 \\
\hline Wheat & 9.7 & 10.2 & 10 \\
\hline Corn gluten meal & 7.3 & 15.8 & 9 \\
\hline Soybean meal & 8.2 & 10 & 8.5 \\
\hline Hydrogenated palm fatty acids & & 40 & 8 \\
\hline Beet pulp & 7.6 & 6 & 6.7 \\
\hline Wheat middlings & 6.6 & & 5.3 \\
\hline Beet molasses & 4.4 & 1.8 & 4.4 \\
\hline Rapeseed meal & 5 & & 4 \\
\hline Limestone & 1.5 & 1.5 & 1.4 \\
\hline Magnesium oxide & 0.2 & 0.4 & 0.2 \\
\hline Sodium chloride & 0.7 & 0.8 & 0.7 \\
\hline Monocalcium phosphate & 0.1 & 0.7 & 0.1 \\
\hline Mineral and vitamin premix ${ }^{1}$ & 0.4 & 0.4 & 0.4 \\
\hline \multicolumn{4}{|l|}{ Nutrient composition } \\
\hline $\mathrm{CP}, \%$ & 17.1 & 17.3 & 17.1 \\
\hline NDF, $\%$ & 29.5 & 6.9 & 24.4 \\
\hline $\mathrm{ADF}, \%$ & 14.9 & 3.33 & 12.8 \\
\hline Ether extract, \% & 3.3 & 37.5 & 11.0 \\
\hline Ash, \% & 6.2 & 5.3 & 5.9 \\
\hline NFC, $\%$ & 43.9 & 33.0 & 41.6 \\
\hline ME, Mcal/kg & 2.62 & 5.14 & 3.12 \\
\hline
\end{tabular}

${ }^{1}$ Premix (provided per kilogram of concentrate): $10,476 \mathrm{IU} / \mathrm{kg}$ of vitamin $\mathrm{A} ; 2,381 \mathrm{IU} / \mathrm{kg}$ of vitamin $\mathrm{D}_{3} ; 27 \mathrm{mg} /$ $\mathrm{kg}$ of vitamin E; $0.3 \mathrm{mg} / \mathrm{kg}$ of $\mathrm{Co}\left(\mathrm{CoCO}_{3}\right) ; 0.95 \mathrm{mg} / \mathrm{kg}$ of I $(\mathrm{CaI}) ; 129 \mathrm{mg} / \mathrm{kg}$ of $\mathrm{Fe}\left(\mathrm{FeSO}_{4}\right) ; 19 \mathrm{mg} / \mathrm{kg}$ of $\mathrm{Mn}$ $(\mathrm{MnO}) ; 32 \mathrm{mg} / \mathrm{kg}$ of $\mathrm{Zn}(\mathrm{ZnO}) ; 19 \mathrm{mg} / \mathrm{kg}$ of $\mathrm{Cu}\left(\mathrm{CuSO}_{4}\right) ;$ and $0.30 \mathrm{mg} / \mathrm{kg}$ of Se (NaSe).

The extruded feed was produced at the facilities of Feed Design Lab (Venray, the Netherlands) using an extruder and vacuum coater. Before extrusion, the mixed meal (Forfarmers, Lochem, the Netherlands) was ground on a $1-\mathrm{mm}$ screen, and thereafter, sieved on a $1.5-\mathrm{mm}$ screen to remove oversized particles. Before extrusion, $5 \%$ of hydrogenated palm fatty acid prills were included in the meal. The feeding rate of the extruder was adjusted to reach a target bulk density of $400 \mathrm{~g} / \mathrm{L}$. Conditioning was regulated to reach 25 to $28 \%$ of moisture (e.g., from ingredients plus water and steam), minimum temperature was $95^{\circ} \mathrm{C}$, and steam pressure of the conditioner was set at 200,000 Pa. The outlet of the extruder held 6 die inserts with a conical inlet and a measured land

Table 2. Pellet mix and analyzed nutrient composition of the 5 solid feed treatments

\begin{tabular}{|c|c|c|c|c|c|}
\hline \multirow[b]{2}{*}{ Item } & \multicolumn{5}{|c|}{ Starter feed ${ }^{1}$} \\
\hline & Control & $90: 10$ & $80: 20$ & $70: 30$ & HFSP \\
\hline \multicolumn{6}{|c|}{ Ingredient, $\%$ of total starter feed } \\
\hline Low-fat pellet & 100 & 90 & 80 & 70 & - \\
\hline High-fat extruded pellet & - & 10 & 20 & 30 & - \\
\hline High-fat single pellet & - & - & - & - & 100 \\
\hline \multicolumn{6}{|l|}{ Nutrient, DM basis } \\
\hline $\mathrm{CP}, \%$ & 17.1 & 17.1 & 17.1 & 17.2 & 17.1 \\
\hline NDF, $\%$ & 29.5 & 27.4 & 25.1 & 22.6 & 24.4 \\
\hline $\mathrm{ADF}, \%$ & 14.9 & 13.7 & 12.4 & 11.3 & 12.8 \\
\hline Ether extract, \% & 3.3 & 6.8 & 10.1 & 13.4 & 11.0 \\
\hline Ash, \% & 6.2 & 6.1 & 6.0 & 5.9 & 5.9 \\
\hline $\mathrm{NFC}, \%$ & 43.9 & 42.8 & 41.7 & 40.6 & 41.6 \\
\hline $\mathrm{ME},{ }^{2} \mathrm{Mcal} / \mathrm{kg}$ & 2.62 & 2.87 & 3.12 & 3.38 & 3.12 \\
\hline
\end{tabular}


length of 6.7 and $4 \mathrm{~mm}$ diameter. Total die open area was $75.4 \mathrm{~mm}^{2}$. After extrusion, the product was dried at $110^{\circ} \mathrm{C}$ for about $30 \mathrm{~min}$ and subsequently conveyed from the dryer to the coating line pneumatically. Then, a vacuum coater was used to flood the hot pellets with approximately $35 \%$ heated hydrogenated palm fatty acids. Thereafter, the product was cooled and packed.

\section{Measurements}

Calves were weighed using an electronic weighing scale at birth and on a weekly basis thereafter. Individual MR and solid feed consumption (both pellets and straw) were determined daily by measuring leftovers. Feeds and pooled refusals were analyzed for DM $\left(4 \mathrm{~h}\right.$ at $\left.103^{\circ} \mathrm{C}\right)$, ash $\left(550^{\circ} \mathrm{C}\right.$ calcination), and $\mathrm{CP}$ with and automatic distiller Kjeldahl (Kjeltec Auto 1030 Analyzer, Tecator) with copper sulfate/selenium as a catalyst instead of copper sulfate/titanium dioxide (method 988.05; AOAC International, 2000), NDF was analyzed with sodium sulfite and heat-stable $\alpha$-amylase (Van Soest et al., 1991), ADF was analyzed following (Robertson and Van Soest, 1981), and ether extract following the method 920.39 from AOAC (1990) with petroleum ether used for distillation instead of diethyl ether (AOAC International, 2000) with previous acid hydrolysis (Stoldt, 1952).

At 49 and $84 \mathrm{~d}$ of life, 10 calves per treatment were randomly selected, blocked by initial BW, and subjected to a glucose tolerance test (GTT) to assess insulin sensitivity following Bach et al. (2013). Briefly, each calf received an intravenous infusion of $180 \mathrm{mg} / \mathrm{kg}$ of BW of glucose $5 \mathrm{~h}$ after the morning meal. The 5 -h interval from last meal was chosen because it has been proposed that changes in insulin sensitivity in calves are more evident after eating, when a decrease occurs in the number of insulin receptors (Hugi et al., 1998). An indwelling catheter (Abbocath-T 16 gauge $\times 140 \mathrm{~mm}$; Hospira Inc., Lake Forest, IL) was placed in the left jugular vein. The catheter was used to infuse glucose (500 g/L of glucose anhydrous; B. Braun Medical, Terrassa, Spain) and to collect blood samples. Blood was harvested in 4-mL evacuated tubes containing a glycolysis inhibitor (BD Vacutainer fluoride tubes, Becton Dickinson, Madrid, Spain) to determine plasma glucose concentrations, and 5 -mL evacuated tubes containing EDTA (BD Vacutainer serum tubes) for plasma insulin determinations. Blood samples were obtained at -15 , $-5,0,4,8,12,18,25,35,45,60$, and 120 min relative to glucose infusions. Catheter patency was maintained by flushing with $5 \mathrm{~mL}$ of heparinized saline solution (1,000 USP units of heparin/mL).
At $21,49,56,70$, and $84 \mathrm{~d}$ of life, feeding, resting, and rumination behavior of all calves was monitored for $4 \mathrm{~h}$ after the morning feeding using scan sample technique as described elsewhere (Terré et al., 2013). On the same days, blood samples were obtained before the morning feeding to determine plasma concentration of $\beta$-OH-butyrate and cholecystokinin (CCK). Plasma concentrations of $\beta-\mathrm{OH}$ butyrate were determined using a colorimetric technique with a commercial kit (Randbut, Randox Laboratories Limited, Crumlin, United Kingdom) and CCK plasma concentrations were measured using RIA as described by Villalba et al. (2011) with an intraassay coefficient of variation of less than $2.6 \%$.

The kit used for CCK determination binds to CCK-8 sulfate and cross-reacts with CCK-33 sulfate.

Total-tract DM and ether extract digestibility was performed on 7 calves per treatment, which were randomly chosen between 70 and $75 \mathrm{~d}$ of age using indigestible NDF as a marker to estimate fecal output (Oba and Allen, 2003). Indigestible NDF was determined after $120 \mathrm{~h}$ of in vitro rumen incubation following Goering and Van Soest (1970).

Pellet hardness (which measures the compression force required to fragment a pellet into small particles and fines expressed in $\mathrm{kg}$ ) was determined following the method described by Thomas and van der Poel (1996), and pellet durability (expressed as the ratio of the weight after tumbling over the weight before tumbling) was determined following the procedure described by Pfost (1963). In brief, pellet hardness was assessed using a Kahl device, and pellet durability was determined using a tumbling rotating device and quantifying the proportion of particles $<2.5 \mathrm{~mm}$.

\section{Calculations and Statistical Analysis}

Sorting activity for fat in the solid feed was calculated as the actual fat intake expressed as a percentage of the predicted intake, which was calculated as the difference between the amount of fat in the feed offered and that in the feed refused. The predicted fat intake was calculated as the product of DMI of the total diet times the percentage of fat in the offered feed. Values equal to $100 \%$ indicate no sorting, $<100 \%$ indicate selective refusals (sorting against), and $>100 \%$ indicate preferential consumption (sorting for). Values for sorting were tested for potential difference from $100 \%$ using a $t$-test.

Calculations for insulin sensitivity followed Bach et al. (2013). In brief, blood samples collected at $-15,-5$, and 0 min relative to glucose infusion were averaged 
to determine baseline concentrations of both glucose and insulin. Then, the area under the curve for these 2 metabolites was calculated as the increase with respect to the baseline using the trapezoidal method.

Performance and blood data were analyzed using a mixed-effects model accounting for the fixed effects of treatment, time of measurement, and their 2-way interaction, and the random effect of calf. Time entered the model as a repeated measure using an autoregressive covariance matrix. Digestibility data were analyzed using an ANOVA with treatment as the main effect. Behavior data were summarized individually as the total time (min) devoted to each monitored behavior. Then, each behavior was expressed as a percentage of total observed behaviors and the data analyzed in the same fashion as the performance data.

\section{RESULTS AND DISCUSSION}

The current study was designed to evaluate potential differences on performance between birth and 4 wk postweaning of different levels of fat supplementation in solid feeds by either combining regular pellets with a high-fat pellet in extruded form or by directly feeding a regular HFSP. Higher inclusion levels of the extruded high-fat pellet increased ME content by fat inclusion; however, the nutrient content of the 80:20 pellet combination and that of HFSP was almost identical (with the exception of slightly lower ether extract content in 80:20 than in HFSP), yet the fat was included in a different physical form. Because solid feed treatments were iso-nitrogenous across the different inclusion levels of the extruded pellet, energy:protein ratio changed (Table 2); thus, the potential effect of different energy: protein ratio on intake or other relevant output parameters among some solid feed treatments cannot be separated from the net addition of fat. This is an important aspect to take into consideration when evaluating the effects reported herein. Additionally, feed and energy intake are response variables that can influence other parameters.

All calves consumed their daily MR allowances throughout the study. Starter feed intake was greatest $(P<0.05)$ in 90:10 calves and lowest for the HSFP (Table 3). Previous studies found that increasing the fat content of starter reduced intake (Miller et al., 1959; Kuehn et al., 1994), whereas other researchers observed no negative effect (Johnson et al., 1956; Araujo et al., 2014). These differences in outcome could be explained primarily by the differences in fat sources and to a lesser extent by weaning age and management. For instance, Araujo et al. (2014) reported that fat content of starter feed had no effect on solid feed intake when providing
$750 \mathrm{~g} / \mathrm{d}$ of MR and using full fat soybean as a fat source in the starter feed, which is known to be highly preferred by calves (Montoro and Bach, 2012). However, a similar study (Hill et al., 2015) found reduced intake when feeding starter feeds rich in fat. The different results between Araujo et al. (2104) and Hill et al. (2015) could be linked to the type of fat (e.g., saturation) and the way it was presented to calves. Araujo et al. (2014) used whole soybeans as a source of fat, whereas Hill et al. (2015) used either tallow or soybean oil. Nevertheless, from a feed technology standpoint, the inclusion of fat in single-pellet starters is limited because it negatively affects pellet hardness and durability. In fact, hardness herein was lower in the pellets with high fat, although durability was equivalent among treatments. For low-fat control pellet, extruded high-fat pellet, and HFSP, pellet hardness was 8.1, 5.9, and $5.1 \mathrm{~kg}$, respectively, and pellet durability was $97.8,97.7$, and $97.6 \%$, respectively. Because pellet durability (associated with proportion of fines) was similar among treatments, it is unlikely that differences in intake were due to physical aspects of the calf starter feed in this study. Differences in solid feed intakes were most apparent in the period between weaning, at 8 wk of age, and at the end of the study at 12 wk (Figure 1). No differences were observed in straw intake among treatments, and as previously reported (Castells et al., 2013, 2015), calves maintained the ad libitum consumption of straw to $<10 \%$ of TS feed intake.

As expected (and designed in the experiment), calves in the 70:30 treatment consumed the greatest amount of fat, followed by calves in 80:20 and HFSP that consumed the same amount of fat, and control calves consumed the lowest, with 90:10 calves consuming intermediate values (Table 3). Intake of ME was lowest for control and HFSP calves (Table 3) as a result of the lowest starter ME content in control and low starter feed intake in HFSP calves (Table 2). As occurred with starter intake, differences in ME intake were also more evident between 9 and 12 wk (Figure 2). Interestingly, control and 90:10 calves consumed the same amount (Figure 3A) of fermentable (low-fat pellet), but 90:10 calves still consumed additional energy because they also ingested high-fat pellets (Figure 3B). These results might suggest that maximum intake was limited by the fermentation capacity of the rumen because the amount of fermentable pellets (low-fat) consumed by calves was the same for control and 90:10 treatments. Thus, we hypothesize that calves have a ceiling for maximum starter intake dictated by the capacity of the rumen to ferment solid feed, and that a nonfermentable, high-fat pellet allows calves to consume more energy beyond their maximum capacity to consume fermentable feeds. 


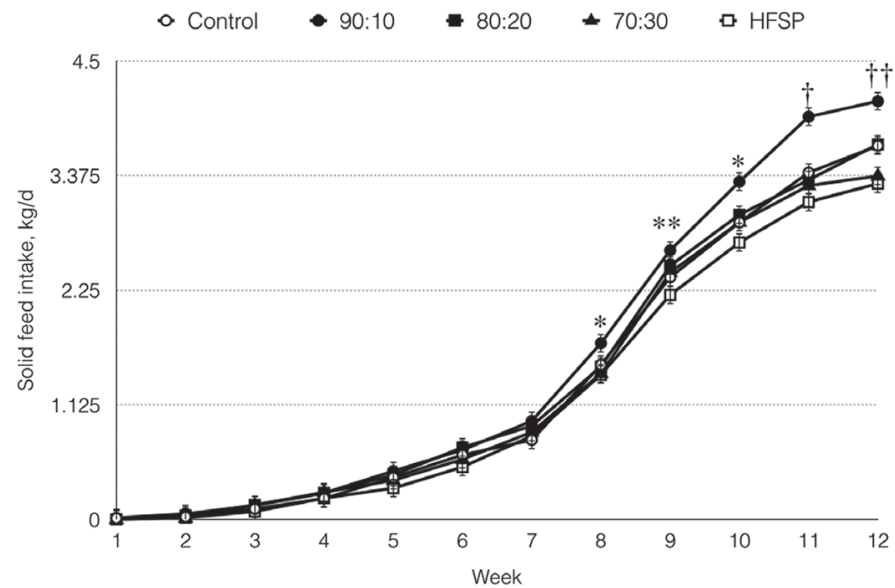

Figure 1. Solid feed intake as affected by treatment. Control $=$ $100 \%$ low-fat pellet; 90:10 $=90 \%$ low-fat, $10 \%$ high-fat; $80: 20=80 \%$ low-fat, $20 \%$ high-fat; $70: 30=70 \%$ low-fat, $30 \%$ high-fat; HFSP $=$ high-fat single pellet. ${ }^{*}$ Denotes differences $(P<0.05)$ between 90:10 and the rest of treatments; ${ }^{*}$ Denotes differences $(P<0.05)$ between 90:10 and HFSP. †Denotes differences between 90:10 and the rest of treatments and between 80:20, 70:30, and control versus HFSP. $\dagger \dagger$ Denotes differences between 90:10 and the rest of treatments and between 80:20 and control versus control and HFSP. Error bars indicate SE.

In that sense, observed effects are expected to depend on weaning age and strategy. Rumen development is considered incomplete before 8 wk of age (Meale et al., 2017). More gradual (Meale et al., 2015) or delayed weaning (Eckert et al., 2015; Wood et al., 2015) could allow more time for rumen development and reduce the contrasts among treatments. On the other hand, calves on the $80: 20$ or $70: 30$ treatments did not consume more ME than 90:10 calves, and thus it seems that in these cases feed intake was limited by total energy supply from solid feed. In fact, plasma CCK concentrations were greatest in 80:20 calves, although did not differ from those in 90:10, 70:30, and HFSP (Table 4). Cholecystokinin is a gut peptide secreted in response to the presence of fat and protein in the upper small intestine (Liddle et al., 1985). Increased concentrations of CCK have been linked to depression of appetite and intake in both adult cattle (Allen and Piantoni, 2013) and young calves (Montoro et al., 2012), and thus it could be speculated that CCK or other hormones could be acting at a metabolic level limiting intake of solid feed when the concentration of fat in the solid feed is high. In fact, in the current study, plasma CCK concentrations followed the same pattern as fat intake. Lastly, consumption of ME with the HSFP treatment was equivalent to that of control calves, and in this case, it could be speculated that intake was limited by both a lack of fermentation activity in the rumen (and thus poor rumen development) and a high energy density of the starter feed (and metabolic inhibition of intake). However, blood $\beta$-OH-butyrate concentrations, which were similar among treatments except for HFSP, which was greatest (Table 4), a priori, do not seem to corroborate the hypothesis of limited rumen development with HFSP treatment. Blood $\beta-\mathrm{OH}$-butyrate concentrations have been associated with rumen development because it is a product of rumen cell wall while metabolizing butyrate (Weigand et al., 1972). However, blood $\beta-\mathrm{OH}-$ butyrate concentrations could also have originated from the partial oxidation of fatty acids (from both MR and high-fat starter feeds) in the liver, which is increased in high-fat diets due to alterations in the oxidation process within the mitochondrion (Vial et al., 2011). An alternative hypothesis for the equivalent ME consumption between HSFP and control calves could be found in a decreased apparent DM digestibility with

Table 3. Performance and intake of young calves until $12 \mathrm{wk}$ of age as affected by treatments

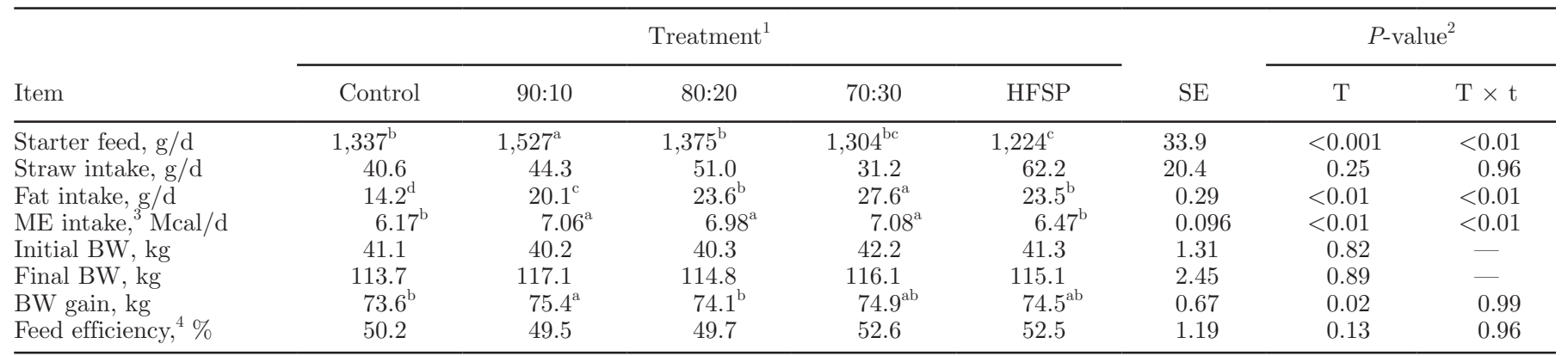

\footnotetext{
${ }^{\mathrm{a}-\mathrm{d}}$ Values with uncommon superscripts differ at $P<0.05$.

${ }^{1}$ Control $=100 \%$ low-fat pellet; 90:10 = 90\% low-fat, 10\% high-fat; 80:20 = 80\% control, $20 \%$ high-fat; $70: 30=70 \%$ control, $30 \%$ high-fat; HFSP $=$ high-fat single pellet.

${ }^{2} \mathrm{~T}=$ effect of treatment; $\mathrm{T} \times \mathrm{t}=$ interaction between treatment and time.

${ }^{3}$ Calculated following NRC (2001).

${ }^{4}$ Calculated as [weight gain $(\mathrm{g} / \mathrm{d}) /$ feed intake $\left.(\mathrm{g} / \mathrm{d})\right] \times 100$.
} 

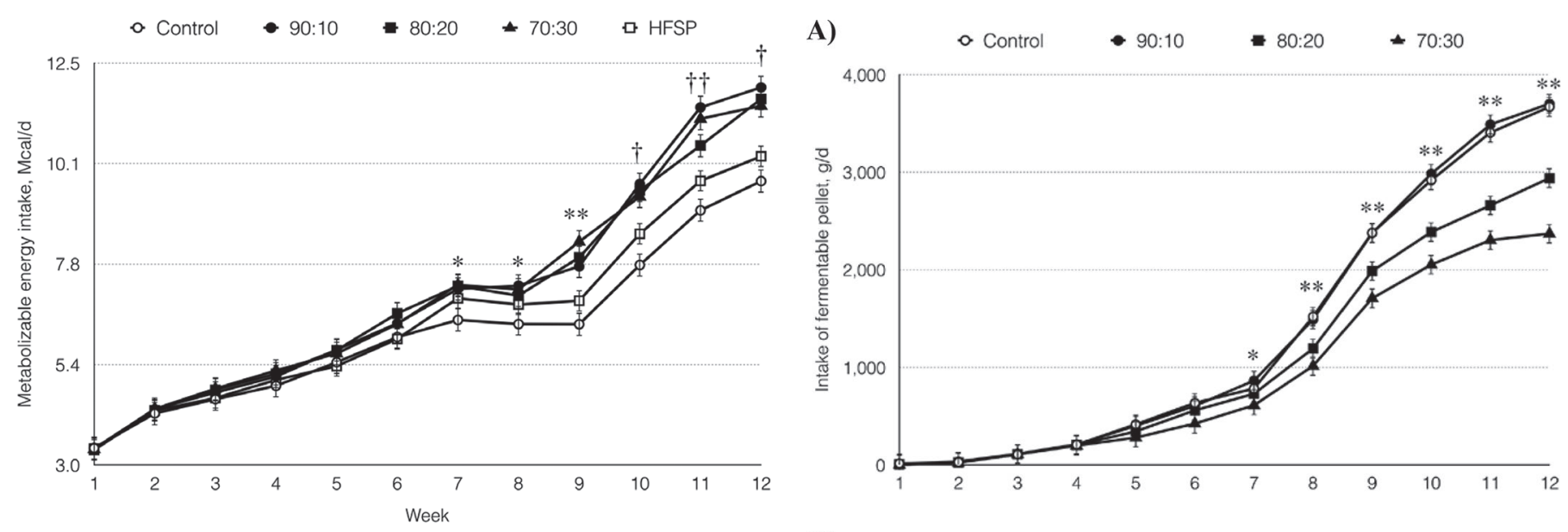

Figure 2. Intake of ME (Mcal/d) as affected by treatment. Control $=100 \%$ low-fat pellet; $90: 10=90 \%$ low-fat, $10 \%$ high-fat; $80: 20: 80 \%$ low-fat, $20 \%$ high-fat; $70: 30=70 \%$ low-fat, $30 \%$ high-fat; HFSP $=$ high-fat single pellet. ${ }^{*}$ Denotes differences $(P<0.05)$ between 90:10, 80:20, and 70:30 versus control. **Denotes differences $(P<0.05)$ between 70:30 and 90:10, and between 90:10, 80:20, and 70:30 versus control and HFSP. †Denotes differences $(P<0.05)$ between 90:10, 80:20, and 70:30 versus control and HFSP, and differences between control and HFSP. ††Denotes differences $(P<0.05)$ between 90:10 and 70:30 versus 80:20, and between 90:10, 80:20, and 70:30 versus control and HFSP, and differences between control and HFSP. Error bars indicate SE.

HFSP (Table 5). Total-tract apparent DM digestibility was greatest in calves fed 80:20 and 70:30 and lowest for calves fed HFSP, but no differences were observed among treatments on total-tract apparent digestibility of ether extract (Table 5). Interestingly, DM apparent digestibility was substantially greater in 80:20 than in HFSP calves. The fact that both treatments had similar amounts of fat clearly illustrates the negative effects on digestibility of mixing high levels of fat in a single pellet.

The observed differences in DM and ME intake were not reflected in differences in final BW. However, BW gain was greatest with the 90:10 treatment, although it did not differ from the BW gain obtained with the 70:30 and HSFP treatments (Table 3). Accretion of BW was lowest in the control and 80:20 treatments. It is in-

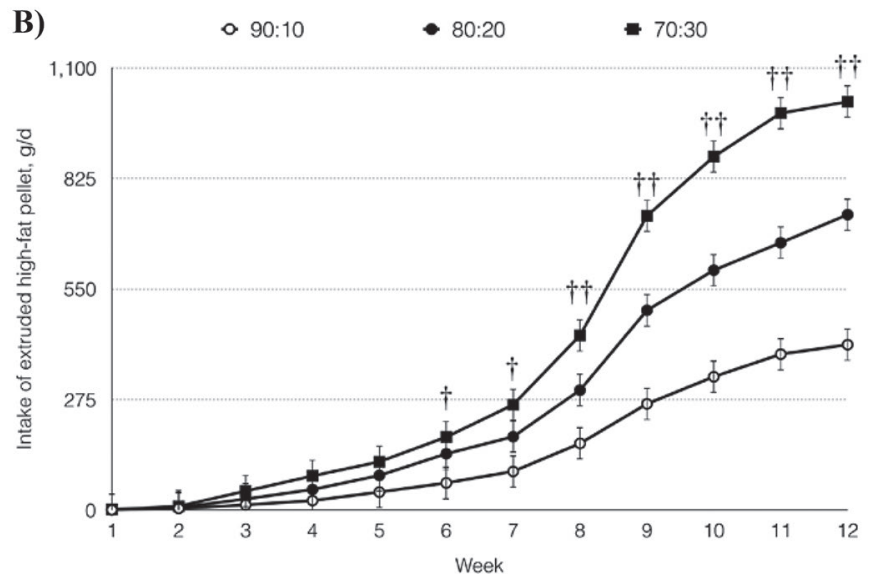

Figure 3. Intake (g/d) of fermentable low-fat pellet (A) and extruded high-fat pellet (B) as affected by treatment. Control $=100 \%$ low-fat pellet; $90: 10=90 \%$ low-fat, 10\% high-fat; 80:20: $80 \%$ low-fat, $20 \%$ high-fat; $70: 30=70 \%$ low-fat, $30 \%$ high-fat pellet. ${ }^{*}$ Denotes differences $(P<0.05)$ between 90:10 versus 70:30; ${ }^{* *}$ Denotes differences $(P<0.05)$ between control and 90:10 versus 80:20 and 70:30, and between 80:20 and 70:30. †Denotes differences $(P<0.05)$ between 90:10 and 70:30. ††Denotes differences $(P<0.05)$ among all 3 fat-containing treatments. Error bars indicate SE.

teresting to note that BW gain did not follow the same patter as ME intake, which was greater in 80:20 than in control calves. Probably variation in homeorhesis (or energy distribution for different physiological tasks or

Table 4. Plasma $\beta$-OH-butyrate and cholecystokinin (CKK) concentrations as affected by treatment

\begin{tabular}{|c|c|c|c|c|c|c|c|c|c|}
\hline Item & \multicolumn{5}{|c|}{ Treatment $^{1}$} & SE & \multicolumn{3}{|c|}{$P$-value ${ }^{2}$} \\
\hline$\overline{\beta \text {-OH-butyrate, } \mathrm{m} M}$ & $0.164^{\mathrm{b}}$ & $0.158^{\mathrm{b}}$ & $0.164^{\mathrm{b}}$ & $0.156^{\mathrm{b}}$ & $0.183^{\mathrm{a}}$ & 0.007 & $<0.01$ & $<0.001$ & 0.10 \\
\hline
\end{tabular}

$\overline{\mathrm{a}, \mathrm{b}}$ Values with uncommon superscripts within a row differ at $P<0.05$.

${ }^{1}$ Control $=100 \%$ low-fat pellet; $90: 10=90 \%$ low-fat, 10\% high-fat; 80:20 = 80\% low-fat, 20\% high-fat; 70:30 = 70\% low-fat, 30\% high-fat; HFSP $=$ high-fat single pellet.

${ }^{2} \mathrm{~T}=$ effect of treatment; $\mathrm{t}=$ effect of time; $\mathrm{T} \times \mathrm{t}=$ interaction between treatment and time. 
Table 5. Digestibility of DM and fat from solid feed of 10-wk-old calves as affected by treatment

\begin{tabular}{|c|c|c|c|c|c|c|c|}
\hline \multirow[b]{2}{*}{ Item } & \multicolumn{5}{|c|}{ Treatment $^{1}$} & \multirow[b]{2}{*}{$\mathrm{SE}$} & \multirow{2}{*}{$\frac{\mathrm{P} \text {-value }}{\mathrm{T}}$} \\
\hline & Control & $90: 10$ & $80: 20$ & $70: 30$ & HFSP & & \\
\hline$\overline{\mathrm{DM}}, \%$ & $74.6^{\mathrm{b}}$ & $74.2^{\mathrm{b}}$ & $76.7^{\mathrm{a}}$ & $78.3^{\mathrm{a}}$ & $69.4^{\mathrm{c}}$ & 0.80 & $<0.001$ \\
\hline Fat, \% & 92.7 & 80.0 & 80.7 & 86.7 & 85.8 & 3.46 & 0.09 \\
\hline
\end{tabular}

tissues) could explain the different response in growth rate observed herein. For example, an increased intake of energy, especially in the form of fat, is expected to lead to differences in body composition. In fact, inclusion of high contents of fat in MR has been shown to increase fat deposition in young calves (Tikovsky et al., 2001; Bascom et al., 2007; Hill et al., 2008).

Inclusion of fat in ruminant diets can improve energy efficiency due to direct use of fatty acids in the metabolic pathways of fat synthesis without the need for acetate and glucose (Machmuller et al., 2000). During the weaning period, the relatively low energy intake due to poor solid feed consumption (Eckert et al., 2015) could be potentially (and partially) compensated by increasing dietary fat in the starter feed. Despite this potential advantage, the use of fat is limited in calf starters due to technological difficulties. Feeding rumen inert fats separate from the pellets is not considered an option for starter feeds because of poor palatability. Furthermore, physical mixing is unfeasible because particle size of fat prills is small in comparison with pellets. However, in the current study, mixing was plausible because extrusion and vacuum coating feed technology allows for similarly sized pellets. In the current study, sorting was negligible as shown by analyses of feed refusals (Table 6). No differences were observed in lying, standing, ruminating, and drinking behavior among treatments, except for the daily proportion of time that calves spent eating, which increased with the 70:30 treatment (Table 6). This could be potentially attributed to a reduced pellet hardness of the high-fat extruded pellet in comparison with the low-fat pellet.

The glucose tolerance tests at both ages revealed no differences in insulin kinetics, although peak glucose concentrations tended $(P=0.06)$ to be greater in HFSP than in 80:20 and 70:30 treatments. Furthermore, AUC for plasma glucose concentration for the $120 \mathrm{~min}$ following a GTT was greatest in 80:20, intermediate in 70:30, HFSP, and control, and lowest in 90:10 calves (Table 7). Interestingly, control and 90:10 calves consumed the same amount of fermentable pellet, but 90:10 calves responded with a lower accumulation of glucose in plasma in the GTT. These data would suggest that the additional ME consumed in 90:10 compared with control calves had a positive effect in glucose metabolism. In a natural (cow-calf) situation, calves would feed on glucose and fat for a longer period of time because of gradual weaning. However, when dietary fat was increased (80:20, 70:30, and HFSP), glucose accumulated in blood following a GTT. Thus, it seems that feeding

Table 6. Animal behavior (\% of daily observations) and fat sorting in the solid feed as affected by treatment

\begin{tabular}{|c|c|c|c|c|c|c|c|c|c|}
\hline Item & \multicolumn{5}{|c|}{ Treatment $^{1}$} & $\mathrm{SE}$ & \multicolumn{3}{|c|}{$P$-value ${ }^{2}$} \\
\hline Lying, \% & 54.4 & 54.6 & 53.1 & 53.2 & 51.9 & 1.62 & 0.70 & 0.09 & 0.33 \\
\hline Ruminating, \% & 9.6 & 7.3 & 7.6 & 7.5 & 7.2 & 0.91 & 0.41 & $<0.01$ & 0.96 \\
\hline Eating, \% & $7.7^{\mathrm{b}}$ & $7.6^{\mathrm{b}}$ & $7.6^{\mathrm{b}}$ & $10.4^{\mathrm{a}}$ & $7.7^{\mathrm{b}}$ & 0.65 & $<0.01$ & $<0.01$ & 0.25 \\
\hline Drinking, \% & 1.5 & 1.4 & 1.6 & 1.4 & 1.6 & 0.20 & 0.90 & 0.27 & 0.37 \\
\hline
\end{tabular}

${ }^{\mathrm{a}, \mathrm{b}}$ Values with uncommon superscripts differ at $P<0.05$.

${ }^{1}$ Control $=100 \%$ low-fat pellet; 90:10 = 90\% low-fat, 10\% high-fat; 80:20 = 80\% low-fat, 20\% high-fat; 70:30 = 70\% low-fat, 30\% high-fat; HFSP $=$ high-fat single pellet.

${ }^{2} \mathrm{~T}=$ effect of treatment; $\mathrm{t}=$ effect of time; $\mathrm{T} \times \mathrm{t}=$ interaction between treatment and time.

${ }^{3}$ Sorting $(\%)=100 \times($ fat intake/fat intake predicted). Sorting values equal to $100 \%$ indicate no sorting, $<100 \%$ indicate selective refusals (sorting against), and $>100 \%$ indicate preferential consumption (sorting for). Data are averaged over $7 \mathrm{~d}$ for each week for 15 calves per treatment. 
Table 7. Parameters of the glucose tolerance test (GTT) performed at 49 and $84 \mathrm{~d}$ of life as affected by treatment

\begin{tabular}{|c|c|c|c|c|c|c|c|c|c|}
\hline Item & \multicolumn{5}{|c|}{ Treatment $^{1}$} & $\mathrm{SE}$ & \multicolumn{3}{|c|}{$P$-value ${ }^{2}$} \\
\hline Basal glucose, ${ }^{3} \mathrm{mg} / \mathrm{dL}$ & 91.9 & 92.3 & 90.8 & 86.9 & 91.3 & 1.86 & 0.21 & 0.23 & 0.71 \\
\hline Peak glucose ${ }^{5} \mathrm{mg} / \mathrm{dL}$ & 168.6 & 165.0 & 163.1 & 160.0 & 171.2 & 2.94 & 0.06 & 0.22 & 0.48 \\
\hline Peak insulin, ${ }^{6} \mu \mathrm{U} / \mathrm{mL}$ & 4.73 & 4.94 & 4.64 & 3.81 & 4.98 & 0.33 & 0.13 & $<0.001$ & 0.83 \\
\hline $\mathrm{Cr}_{\mathrm{sl} \text { cose. }}{ }^{7} \% / \mathrm{min}$ & 6.04 & 8.53 & 7.08 & 6.13 & 7.96 & 0.93 & 0.26 & 0.42 & 0.95 \\
\hline Time to glucose baseline ${ }^{11} \mathrm{~min}$ & 137.5 & 114.7 & 145.7 & 155.6 & 125.1 & 21.02 & 0.67 & 0.31 & 0.57 \\
\hline Time to insulin baseline, ${ }^{11} \mathrm{~min}$ & 44.65 & 40.25 & 48.90 & 44.45 & 59.33 & 7.11 & 0.41 & 0.25 & 0.77 \\
\hline Insulin/glucose ratio ${ }^{12}$ & 6.22 & 6.63 & 5.53 & 4.47 & 10.97 & 1.79 & 0.11 & 0.07 & 0.27 \\
\hline $\mathrm{Si}^{13}(\mathrm{pM} / \mathrm{mL})^{-1}$ per min & 6.91 & 6.77 & 6.95 & 6.83 & 6.94 & 0.06 & 0.25 & 0.24 & 0.39 \\
\hline $\mathrm{Sg},{ }^{14}$ per min & 3.86 & 3.60 & 3.92 & 3.65 & 3.89 & 0.17 & 0.59 & 0.92 & 0.43 \\
\hline
\end{tabular}

${ }^{a-c}$ Values with uncommon superscripts differ at $P<0.05$.

${ }^{1}$ Control $=100 \%$ low-fat pellet; 90:10 $=90 \%$ low-fat, 10\% high-fat; 80:20 = 80\% low-fat, $20 \%$ high-fat; 70:30 = 70\% low-fat, 30\% high-fat; HFSP $=$ single high-fat pellet.

${ }^{2} \mathrm{~T}=$ effect of treatment; $\mathrm{d}=$ effect of day; $\mathrm{T} \times \mathrm{d}=$ interaction between treatment and day.

${ }^{3}$ Average glucose concentration in blood samples taken before the start of the GTT.

${ }^{4}$ Average insulin concentration in blood samples taken before the start of the GTT.

${ }^{5}$ The maximum glucose concentration measured during the GTT.

${ }^{6}$ The maximum insulin concentration measured during the GTT.

${ }^{7}$ Clearance rate of glucose determined following Pires et al. (2007).

${ }^{8}$ Clearance rate of insulin determined following Pires et al. (2007).

${ }^{9}$ Area under the curve (calculated using the trapezoidal method) of glucose during the first 120 min of the GTT.

${ }^{10}$ Area under the curve (calculated using the trapezoidal method) of insulin during the first 120 min of the GTT.

${ }^{11}$ Time to glucose or insulin baseline determined following Pires et al. (2007).

${ }^{12}$ Area under the curve of glucose/area under the curve of insulin.

${ }^{13}$ Insulin sensitivity index derived using the minimal model.

${ }^{14}$ Glucose effectiveness derived using the minimal model (Christoffersen et al., 2009).

large amounts of fat compromises some aspects of glucose metabolism in young calves.

From an evolutionary perspective, calves are naturally weaned at 6 to 8 mo (Reinhardt and Reinhardt, 1981) and thus dietary fat as a source of digestible energy is part of their diet for a longer time than in common practice in the dairy industry. An advantage of solid feeding over milk feeding would be that calves receive this fat source in a gradual manner throughout the day following patterns of rumen retention and passage. Given the low feeding frequency of milk feeding generally applied in the dairy industry (typically twice daily) providing fat via the solid feed may be beneficial in terms of constancy in nutrient supply. In addition, whole milk is greater in fat content than MR; therefore, providing additional dietary fat may deliver a nutrient profile that is closer to that found under natural conditions (cow-calf). This hypothesis is further supported by the final nutrient composition consumed by calves offered free-choice in a cafeteria feeding experiment by Montoro and Bach (2012), where fat content averaged $6.3 \%$, which is greater than fat content generally ob- served in calf diets postweaning and is closest to the treatment with the highest intake in the current study.

\section{CONCLUSIONS}

Delivering dietary fat (to about $7 \%$ of DM) by mixing an extruded high-fat pellet with a high-carbohydrate low-fat conventional pellet, and thus maintaining the supply of fermentable carbohydrates while increasing the energy density of the solid feed results in improved solid feed intake, energy intake, and rate of BW gain when compared with a conventional low-fat pellet, or a single pellet with increased fat content.

\section{ACKNOWLEDGMENTS}

We thank Seong-Chuo Chua (ARC Skretting, Stavanger, Norway) and Wim van Lanen (Boxmeer, the Netherlands) for their help and expertise on feed and production technology. Marko Schuring (Trouw Nutrition Research and Development, Boxmeer, the Netherlands) is gratefully acknowledged for his technical expertise 
in diet formulation and feed technology. This research was partially supported by Trouw Nutrition Research and Development (Boxmeer, the Netherlands) and the Centres de Recerca de Catalunya, Barcelona, Spain, program from Generalitat de Catalunya.

\section{REFERENCES}

Allen, M. S., and P. Piantoni. 2013. Metabolic control of feed intake. Vet. Clin. North Am. Food Anim. Pract. 29:279-297. https://doi .org/10.1016/j.cvfa.2013.04.001.

AOAC. 1990. Official Methods of Analysis. Assoc. Off. Anal. Chem., Arlington, VA.

AOAC International. 2000. Official Methods of Analysis. Vol. I. 17th ed. AOAC Int., Arlington, VA.

Araujo, G., M. Terré, and A. Bach. 2014. Interaction between milk allowance and fat content of the starter feed on performance of Holstein calves. J. Dairy Sci. 97:6511-6518.

Bach, A. 2011. Associations between several aspects of heifer development and dairy cow survivability to second lactation. J. Dairy Sci. 94:1052-1057.

Bach, A. 2012. Ruminant Nutrition Symposium: Optimizing Performance of the Offspring: Nourishing and managing the dam and postnatal calf for optimal lactation, reproduction, and immunity. J. Anim. Sci. 90:1835-1845.

Bach, A., L. Domingo, C. Montoro, and M. Terré. 2013. Short communication: Insulin responsiveness is affected by the level of milk replacer offered to young calves. J. Dairy Sci. 96:4634-4637. https: //doi.org/10.3168/jds.2012-6196.

Bach, A., M. A. Khan, and E. K. Miller-Cushon. 2017. Calf transition: Managing and feeding the calf through weaning. Pages 421-430 in Large Diary Herd Management. 3rd ed. D. K. Beede, ed. American Dairy Science Association, Champaign, IL.

Baldwin, R. L., VI, K. R. McLeod, J. L. Klotz, and R. N. Heitmann. 2004. Rumen development, intestinal growth and hepatic metabolism in the pre- and postweaning ruminant. J. Dairy Sci. 87(E. Suppl.):E55-E65.

Bascom, S. A., R. E. James, M. L. McGilliard, and M. Van Amburgh. 2007. Influence of dietary fat and protein on body composition of Jersey bull calves. J. Dairy Sci. 90:5600-5609.

Berends, H., W. J. J. Gerrits, L. E. Webb, E. A. M. Bokkers, and C. G. van Reenen. 2016. Determinants of feed preferences and intake in calves. Pages 97-98 in Energy and Protein Metabolism and Nutrition. Wageningen Academic Publishers (EAAP publication 137).

Castells, L., A. Bach, A. Aris, and M. Terré. 2013. Effects of forage provision to young calves on rumen fermentation and development of the gastrointestinal tract. J. Dairy Sci. 96:5226-5236. https:// doi.org/10.3168/jds.2012-6419.

Castells, L., A. Bach, and M. Terré. 2015. Short- and long-term effects of forage supplementation of calves during the preweaning period on performance, reproduction, and milk yield at first lactation. J. Dairy Sci. 98:4748-4753. https://doi.org/10.3168/jds.2014-9025.

Christoffersen, B., U. Ribel, K. Raun, V. Golozoubova, and G. Pacini. 2009. Evaluation of different methods for assessment of insulin sensitivity in Gottingen minipigs: Introduction of a new, simpler method. Am. J. Physiol. Regul. Integr. Comp. Physiol. 297:R1195-R1201.

Cowles, K. E., R. A. White, N. L. Whitehouse, and P. S. Erickson. 2006. Growth characteristics of calves fed an intensified milk replacer regimen with additional lactoferrin. J. Dairy Sci. 89:48354845.

Eckert, E., H. E. Brown, K. E. Leslie, T. J. DeVries, and M. A. Steele. 2015. Weaning age affects growth, feed intake, gastrointestinal development, and behavior in Holstein calves fed an elevated plane of nutrition during the preweaning stage. J. Dairy Sci. 98:6315-6326.

Fallon, R. J., P. E. V. Williams, and G. M. Innes. 1986. The effects on feed intake, growth and digestibility of nutrients of including calcium soaps of fat in diets for young calves. Anim. Feed Sci. Technol. 14:103-115.
Goering, H. K., and P. J. Van Soest. 1970. Forage Fiber Analyses (Apparatus, Reagents, Procedures, and Some Applications). Agric. Handbook. No 379. ARS-USDA, Washington, DC.

Hill, S. R., K. F. Knowlton, K. M. Daniels, R. E. James, R. E. Pearson, A. V. Capuco, and R. M. Akers. 2008. Effects of milk replacer composition on growth, body composition, and nutrient excretion in preweaned Holstein heifers. J. Dairy Sci. 91:3145-3155.

Hill, T. M., H. G. Bateman II, J. M. Aldrich, J. D. Quigley, and R. L. Schlotterbeck. 2015. Inclusion of tallow and soybean oil to calf starters fed to dairy calves from birth to four months of age on calf performance and digestion. J. Dairy Sci. 98:4882-4888. https://doi .org/10.3168/jds.2015-9376.

Hugi, D., L. Tappy, H. Sauerwein, R. M. Bruckmaier, and J. W. Blum. 1998. Insulin-dependent glucose utilization in intensively milk-fed veal calves is modulated by supplemental lactose in an age-dependent manner. J. Nutr. 128:1023-1030.

Jasper, J., and D. M. Weary. 2002. Effects of ad libitum milk intake on dairy calves. J. Dairy Sci. 85:3054-3058.

Johnson, D. Jr., K. L. Dolge, J. E. Rousseau Jr., R. Teichman, and H. D. Eaton. 1956. Effect of addition of inedible tallow to a calf starter fed to Holstein calves. J. Dairy Sci. 39:1268-1279.

Kazemi-Bonchenari, M., M. Mirzaei, M. Jahani-Moghadam, A. Soltani, E. Mahjoubi, and R. A. Patton. 2016. Interactions between levels of heat-treated soybean meal and prilled fat on growth, rumen fermentation, and blood metabolites of Holstein calves. J. Anim. Sci. 94:4267-4275.

Khan, M. A., A. Bach, D. M. Weary, and M. A. G. von Keyserlingk. 2016. Invited review: Transitioning from milk to solid feed in dairy heifers. J. Dairy Sci. 99:885-902. https://doi.org/10.3168/jds.2015 -9975 .

Khan, M. A., D. M. Weary, and M. A. G. von Keyserlingk. 2011. Invited review: Effects of milk ration on solid feed intake, weaning, and performance in dairy heifers. J. Dairy Sci. 94:1071-1081. https://doi.org/10.3168/jds.2010-3733.

Kuehn, C. S., D. E. Otterby, and J. G. Linn. 1994. The effect of dietary energy concentration on calf performance. J. Dairy Sci. $77: 2621-2629$.

Liddle, R. A., I. D. Goldfine, M. S. Rosen, R. A. Taplitz, and J. A. Williams. 1985. Cholecystokinin bioactivity in human plasma. Molecular forms, responses to feeding, and relationship to gallbladder contraction. J. Clin. Invest. 75:1144-1152.

Machmuller, A., D. A. Ossowski, and M. Kreuzer. 2000. Comparative evaluation of the effects of coconut oil, oilseeds and crystalline fat on methane release, digestion and energy balance in lambs. Anim. Feed Sci. Technol. 85:41-60.

Meale, S. J., F. Chaucheyras-Durand, H. Berends, L. L. Guan, and M. A. Steele. 2017. From pre- to postweaning: Transformation of the young calf's gastrointestinal tract. J. Dairy Sci. 100:5984-5995.

Meale, S. J., L. N. Leal, J. Martín-Tereso, and M. A. Steele. 2015. Delayed weaning of Holstein bull calves fed an elevated plane of nutrition impacts feed intake, growth and potential markers of gastrointestinal development. Anim. Feed Sci. Technol. 209:268-273.

Miller, W. J., J. L. Carmon, and H. L. Dalton. 1959. Influence of high levels of plant and animal fats in calf starters on growth, feed consumption, and palatability. J. Dairy Sci. 42:153-158.

Montoro, C., and A. Bach. 2012. Voluntary selection of starter feed ingredients offered separately to nursing calves. Livest. Sci. 149:6269.

Montoro, C., I. R. Ipharraguerre, and A. Bach. 2012. Blocking opioid receptors alters short-term feed intake and oro-sensorial preferences in weaned calves. J. Dairy Sci. 95:2531-2539. https://doi .org/10.3168/jds.2011-5053.

NRC. 2001. Nutrient Requirements of Dairy Cattle. 7th rev. ed. Natl. Acad. Sci., Washington, DC.

Oba, M., and M. S. Allen. 2003. Effects of corn grain conservation method on feeding behavior and productivity of lactating dairy cows at two dietary starch concentrations. J. Dairy Sci. 86:174183.

Pfost, H. B. 1963. Testing the durability of pelleted feed. Feedstuffs 23:66-68. 
Pires, J. A. A., A. H. Souza, and R. R. Grummer. 2007. Induction of hyperlipidemia by intravenous infusion of tallow emulsion causes insulin resistance in Holstein cows. J. Dairy Sci. 90:2735-2744.

Reinhardt, V., and A. Reinhardt. 1981. Natural sucking performance and age of weaning in Zebu cattle (Bos indicus). J. Agric. Sci. 96:309-312.

Robertson, J. B., and P. J. Van Soest. 1981. The Detergent System of Analysis and Its Application to Human Foods. Cornell University, Ithaca, NY.

Soberon, F., E. Raffrenato, R. W. Everett, and M. E. Van Amburgh. 2012. Preweaning milk replacer intake and effects on long-term productivity of dairy calves. J. Dairy Sci. 95:783-793.

Stoldt, W. 1952. Vorslag zur vereinheitlichung der fettbestimmung in lebensmitteln. Fette Seifen 54:206-207.

Terré, M., M. Devant, and A. Bach. 2006. Performance and nitrogen metabolism of calves fed conventionally or following an enhancedgrowth feeding program during the preweaning period. Livest. Sci. 105:109-119. https://doi.org/10.1016/j.livsci.2006.05.001.

Terré, M., M. Devant, and A. Bach. 2007. Effect of level of milk replacer fed to Holstein calves on performance during the preweaning period and starter digestibility at weaning. Livest. Sci. 110:82-88. https://doi.org/10.1016/j.livsci.2006.10.001

Terré, M., E. Pedrals, A. Dalmau, and A. Bach. 2013. What do preweaned and weaned calves need in the diet: A high fiber content or a forage source? J. Dairy Sci. 96:5217-5225. https://doi.org/10 $.3168 /$ jds.2012-6304.

Thomas, M., and A. F. B. van der Poel. 1996. Physical quality of pelleted animal feed. Criteria for pellet quality. Anim. Feed Sci. Technol. 61:89-112.
Thomas, M., T. van Vliet, and A. F. B. van der Poel. 1998. Physical quality of pelleted animal feed. 3. Contribution of feedstuff components. Anim. Feed Sci. Technol. 70:59-78.

Tikovsky, J. N., M. E. Van Amburgh, and D. A. Ross. 2001. Effect of varying carbohydrate and fat content of milk replacer on body composition of Holstein bull calves. J. Anim. Sci. 79:2260-2267.

Van Soest, P. J., J. B. Robertson, and B. A. Lewis. 1991. Methods for dietary fiber, neutral detergent fiber, non-starch polysaccharides in relation to animal nutrition. Symposium: Carbohydrate methodology, metabolism and nutritional implications in dairy cattle. J. Dairy Sci. 74:3583-3597.

Vial, G., H. Dubouchaud, K. Couturier, C. Cottet-Rousselle, N. Taleux, A. Athias, A. Galinier, L. Casteilla, and X. M. Leverve. 2011. Effects of a high-fat diet on energy metabolism and ROS production in rat liver. J. Hepatol. 54:348-356. https://doi.org/10 .1016/j.jhep.2010.06.044.

Villalba, J. J., A. Bach, and I. R. Ipharraguerre. 2011. Feeding behavior and performance of lambs are influenced by flavor diversity. J. Anim. Sci. 89:2571-2581. https://doi.org/10.2527/jas.2010-3435.

Weigand, E., J. W. Young, and A. D. McGilliard. 1972. Extent of butyrate metabolism by bovine ruminoreticulum epithelium and the relationship to absorption rate. J. Dairy Sci. 55:589-597. https:// doi.org/10.3168/jds.S0022-0302(72)85541-3.

Wood, K. M., S. I. Palmer, M. A. Steele, J. A. Metcalf, and G. B. Penner. 2015. The influence of age and weaning on permeability of the gastrointestinal tract in Holstein bull calves. J. Dairy Sci. 98:7226-7237 